\title{
GRAU DE RELACIONAMENTO ENTRE O RANKING DE INDICADORES DE MERCADO DE CAPITAIS E O RANKING DE INDICADORES ECONÔMICO- FINANCEIROS DE EMPRESAS BRASILEIRAS - UM ESTUDO MULTICRITERIAL POR MEIO DO MÉTODO VIKOR
}

\author{
Itzhak David Simão Kaveski ${ }^{1}$, Nelson Hein², Adriana Kroenke ${ }^{2}$ \\ ${ }^{1}$ Universidade Federal de Mato Grosso do Sul- UFMS/CPAN \\ ${ }^{2}$ Fundação Universidade Regional de Blumenau - FURB \\ itzhak.konoha@gmail.com, heinefurb.br, didlen@terra.com.br
}

\begin{abstract}
Resumo: O estudo objetiva estabelecer o grau de relacionamento entre o ranking de indicadores de mercado de capitais e o ranking de indicadores econômico-financeiros, de empresas brasileiras. Para a realização do estudo foram selecionadas quatro indicadores de mercado de capitais e seis econômico-financeiros, em 27 empresas pertencentes ao índice IBrX-50 listadas na BM\&FBovespa, com análise correspondente aos períodos de 2008 a 2012. Foram estabelecidos os rankings de indicadores econômico-financeiro e de mercado de capitais, por meio do método multicritério VIKOR, para cada um dos anos analisados. Calculou-se a correlação de Kendall entre os dois rankings, que evidenciou correlações positivamente significativas apenas nos anos de 2010, 2011 e 2012. Concluise então que, as empresas para alguns dos anos analisados, tendem a possuir similaridades nas posições de eficiência no mercado de capitais e nos tradicionais indicadores econômico-financeiros, mas em outros apresentaram tanto posições similares como distintas.
\end{abstract}

Palavras-chave: Indicadores de Mercado de Capitais. Indicadores EconômicoFinanceiros. VIKOR.

\section{DEGREE OF RELATIONSHIP BETWEEN THE RANKING OF INDICATORS OF CAPITAL MARKETS INDICATORS AND RANKING OF ECONOMIC- FINANCIAL INDICATORS IN BRAZILIAN COMPANIES - A STUDY MULTICRITERIAL BY THE METHOD VIKOR}

\begin{abstract}
The study aims to establish the degree of relationship between the ranking of capital market indicators and the ranking of economic-financial indicators of brazilian companies. The design of this research is characterized as a descriptive study, with documentary research procedure, and a quantitative approach. For the study were selected four indicators of capital market and six financial-economic, 27 companies belonging to IBrX-50 listed on the BM\&FBovespa, basing the analysis for the periods 2008 to 2012.Were created the rankings of financial-economic and capital markets, through the multicriteria method VIKOR, for each of the years analyzed. We calculated the Kendall correlation between the two rankings, significant positive correlations were observed in the years, 2010, 2011 and 2012. It was concluded that, for some companies the years analyzed, tend to have similarities in positions efficiency in the capital market and the traditional economic-financial indicators, but in other similar positions presented both as distinct.
\end{abstract}

Keywords: Capital Markets Indicators. Economic-Financial Indicators. VIKOR.

R. Eletr. do Alto Vale do Itajaí - REAVI, v. 4, n. 5, p. I- F, mar., 2016.

ISSN 2316-4190, DOI: 10.5965/2316419004052015050 


\section{INTRODUÇÃO}

A relação entre os indicadores de mercado de capitais, os indicadores econômicofinanceiros com o retorno das ações, tem sido foco de grande parte das pesquisas sobre o tema no âmbito internacional e nacional. Estudos com o objetivo de verificar o retorno das ações, não é novo e foi desenvolvido basicamente a partir da década de 1950, por Markowitz (1952), através do seu modelo, proporcionou ao investidor uma abordagem quantitativa principalmente na mensuração do risco, pela otimização de portfólios.

Além de Markowitz (1952), outros pesquisadores elaboraram modelos para analisar o comportamento das ações com base nas informações disponíveis pelo mercado e pela empresa. Dentre estes modelos, destaca-se o modelo de desconto de dividendos de Gordon e Shaphiro (1956), que valoriza o preço das ações por meio do dividendo pago pela empresa. O Modelo de Precificação de Ativos desenvolvido por Sharpe (1964), conhecido como CAPM, o qual implica que a distribuição dos retornos dos ativos é uma função linear dos riscos dos títulos das ações. E o modelo do pesquisador Ohlson (1995), conhecido como modelo de Ohlson, que utiliza a relação entre os lucros anormais e o valor de uma empresa com base em informações contábeis.

Entretanto, foi a partir do estudo de Fama (1970), que ocorreu o crescimento na demanda de estudos sobre o retorno das ações em diversos países. Neste trabalho o autor reorganizou a definição de mercado eficiente, de forma a afirmar que um mercado é eficiente quando os preços de mercado sempre refletem toda a informação disponível, distinguindo em três formas de eficiência, a forma fraca, forma semiforte e a forma forte. Dessa forma, diversos estudos analisaram o retorno das ações nestas três formas de eficiência.

Diversos estudos testaram os modelos supracitados na verificação da relação do retorno da ação com os indicadores econômico-financeiros e os indicadores de mercado de capitais. Apesar da larga quantidade de pesquisas, principalmente na eficiência em sua forma semiforte, a confirmação de que os preços correntes refletem toda informação disponível publicamente das empresas ainda carece de mais estudos. Conforme Fama (1970), cada teste individual neste tipo de eficiência analisa a maneira pela qual os preços se ajustam a uma informação específica. Dessa forma, pode ocorrer uma grande variabilidade de resultados entre os estudos.

A maioria das pesquisas que tratam do tema abordado neste estudo, tem sido desenvolvidas para verificar a relação dos indicadores de mercado de capitais com o retorno das ações, ou a relação dos indicadores econômico-financeiros com o retorno da ação, ou seja, não foi verificado até o momento, se os indicadores de mercado de capitais estão correlacionados com os indicadores econômico-financeiros.

Diante do que foi abordado, percebe-se uma lacuna na literatura, até o momento não foi verificado se os indicadores econômico-financeiros estão relacionados com os indicadores mercado de capitais. Assim, esta pesquisa avança neste aspecto na tentativa de identificar se os indicadores de mercado de capitais e econômico-financeiros possuem relação entre si.

Neste sentido, apresenta-se a questão que norteia a presente pesquisa: Qual o grau de relacionamento entre o ranking de indicadores de mercado de capitais e o ranking de indicadores econômico-financeiros, de empresas brasileiras? Dessa forma, o objetivo da pesquisa é estabelecer o grau de relacionamento entre o ranking de indicadores de mercado de capitais e o ranking de indicadores econômico-financeiros, de empresas brasileiras. 
A justificativa do estudo está alicerçada em três pilares que são de extrema importância para trabalhos científicos, a saber: a originalidade, a não trivialidade e a contribuição cientifica.

A originalidade fica em função de que os temas mercado de capitais e avaliação de desempenho econômico-financeiro são proeminentes na área contábil, ao passo que esses grupos de indicadores utilizados simultaneamente são inovadores. Por sua vez, o método utilizado para a formação dos rankings dos indicadores das empresas, o algoritmo de VIKOR, foi pouco utilizado no Brasil.

Quanto aos aspectos da não trivialidade dos assuntos abordados neste trabalho, relata-se o processo de análise que abarca o método VIKOR, no processo de ranking de indicadores econômico-financeiros e indicadores de mercado de capitais nas empresas pertencentes ao IBrX-50 listadas na BM\&FBovespa, além da comparação dos rankings.

A contribuição cientifica deste trabalho reside na análise da relação entre o posicionamento das empresas quanto aos indicadores econômico-financeiros e dos mercado de capitais, visto que a partir desta investigação foi possível comprovar empiricamente o tipo de relação entre esses indicadores, nas empresas pertencentes ao índice IBrX-50 listadas na BM\&FBovespa.

\section{REVISÃO DA LITERATURA}

\subsection{Indicadores Econômico-Financeiros}

Os indicadores de liquidez buscam medir a capacidade financeira das empresas de saldar suas obrigações de curto prazo, mas não significa que os índices de liquidez indicam a capacidade de pagamento, visto que os dados não são extraídos do fluxo de caixa (MATARAZZO, 2010). De acordo com Assaf Neto (2010, p. 103), "os indicadores de liquidez visam medir a capacidade de pagamento (folga financeira) de uma empresa, ou seja, sua habilidade em cumprir corretamente as obrigações passivas assumidas.”

Os principais índices que medem a liquidez da empresa são Liquidez Geral (LG), Liquidez Corrente (LC) e Liquidez Seca (LS). Todos esses indicadores, conforme Brigham e Houston (1999, p. 80), "são quocientes que mostram a relação entre caixa e outros ativos circulantes de uma empresa e seus passivos circulantes".

O índice de Liquidez Geral (LG) refere-se à relação da soma dos ativos circulantes com o realizável a longo prazo pela soma do passivo circulante com o exigível total, retratando a saúde financeira das organizações a longo prazo (ASSAF NETO, 2010). Entretanto, conforme Iudícibus (2009), é necessário ter cautela quando for utilizar a LG, pois os prazos de recebimento dos ativo circulantes e realizáveis a longo prazo são diferentes da liquidação do passivo circulante e exigível a longo prazo. $\mathrm{O}$ índice LG é determinado da seguinte maneira:

$$
\text { Liquidez Geral (LG) }=\frac{\text { Ativo Circulante }+ \text { Ativo não Circulante }}{\text { Passivo Circulante }+ \text { Passivo não Circulante }}
$$


A relação entre o ativo circulante e o passivo circulante é apresentada por meio da Liquidez Corrente (LC), considerada aquela que melhor indica a situação liquida de curto prazo das organizações (IUDÍCIBUS, 2009). Conforme Assaf Neto (2010), a LC evidencia quanto a empresa possui de recursos financeiros de curto prazo para fazer frente as suas dívidas de curto prazo dentro do período estabelecido. A LC é calculada da seguinte maneira:

$$
\text { Liquidez Corrente (LC) }=\frac{\text { Ativo Circulante }}{\text { Passivo Circulante }}
$$

O índice de Liquidez Seca (LS) refere-se à relação entre os ativos circulantes (eliminando uma fonte maior de incerteza, ou seja, os estoques) e o passivo circulante. Contudo os problemas dos prazos dos ativos e passivos circulantes continuam (IUDÍCIBUS, 2009). Conforme Assaf Neto (2010, p. 104), a LS indica “[...] o percentual das dívidas de curto prazo que pode ser resgatado mediante o uso de ativos circulantes de maior liquidez." A LS é apresentada da seguinte forma:

$$
\text { Liquidez Seca }(\mathrm{LS})=\frac{\text { Ativo Circulante }- \text { Estoques }}{\text { Passivo Circulante }}
$$

Conforme Brealey e Myers (2006) existem ativos que estão mais próximos do caixa do que outros. Os estoques são ativos que pode não ser vendidos acima dos preços de liquidação, problema que ocorre quando o estoque da empresa está cheio e os produtos ainda não foram vendidos. Dessa forma, as empresas se focam em analisar a liquidez da empresa através da LS, pois utiliza-se apenas dos ativos caixa, títulos de curto prazo, e nas contas que os clientes ainda não pagaram.

Os indicadores de rentabilidade, segundo de Assaf Neto (2010, p. 109), “[...] visam avaliar os resultados auferidos por uma empresa em relação a determinados parâmetros que melhor revelem suas dimensões." Conforme Matarazzo (2010), estes indicadores proporcionam a avaliação de rendimento obtido por meio do capital investido na empresa. Diversos indicadores podem ser utilizados para avaliar a rentabilidade.

O índice do Giro do Ativo Total (GAT) refere-se ao número de vezes que o ativo total da empresa girou em determinado exercício em função das receitas líquidas (MATARAZZO, 2010; PINHEIRO, 2012). Conforme os autores, quanto maior for o Giro do Ativo da empresa, melhor terá sido o seu desempenho com os retornos de suas aplicações. O GAT é calculado da seguinte maneira:

$$
\text { Giro do Ativo Total }(\mathrm{GAT})=\frac{\text { Receitas Líquidas }}{\text { Ativo Total }}
$$

O índice que relaciona o lucro líquido com o patrimônio líquido é chamado de Rentabilidade do patrimônio líquido (ROE). Este indicador representa o retorno dos recursos aplicados pelos acionistas na empresa (ASSAF NETO, 2010; MATARAZZO, 2010). O índice ROE é determinado da seguinte maneira:

$$
\text { Rentabilidade do Patrimônio Líquido }(\mathrm{ROE})=\frac{\text { Lucro Líquido }}{\text { Patrimônio Líquido }}
$$

A relação entre o lucro líquido e o ativo total é denominada como Retorno sobre o Ativo (ROA), que mede a eficiência que a empresa possui em gerar lucros a partir de seus ativos (DAMODARAN, 1997). Este indicador mede o potencial que uma empresa 
tem na geração de lucro, para que a mesma possa capitalizar-se (DAMODARAN, 1997; ASSAF NETO, 2010; MATARAZZO, 2010). O ROA é apresentado da seguinte forma:

$$
\text { Retorno sobre o Ativo }(\mathrm{ROA})=\frac{\text { Lucro Líquido }}{\text { Ativo Total }}
$$

Gontijo e Maia (2004, p. 13) ressaltam que “a complexidade dos negócios exige respostas rápidas dos indivíduos ou grupos de indivíduos que são responsáveis por algum tipo de organização", e que são obrigados a tomar decisões constantemente. Essa atividade decisória é determinante para o sucesso das organizações, já que a escolha entre ter uma empresa com maior liquidez ou rentabilidade, influencia diretamente seu desempenho.

\subsection{Indicadores de Mercado de Capitais}

De acordo com Damodaran, (1997, p. 359), o PER “é uma informação estatística intuitivamente interessante que relaciona o preço pago aos lucros atuais". Assaf Neto (2010) salienta que os valores obtidos pelo PER são válidos apenas para a data de sua apuração, uma vez que os valores obtidos pela forma de cálculo sofrem contínuas variações conforme o tempo. Segundo Pinheiro (2012), o PER possui utilidade universal, ou seja, pode-se aplicar em todo tipo de empresa, sem ter prejuízos com o setor. $\mathrm{O}$ índice PER é determinado da seguinte maneira:

$$
\text { Price Earning Ratio }(\mathrm{PER})=\frac{\text { Valor de Mercado }}{\text { Lucro por Ação }}
$$

Conforme Damodaran (1997), o indicador fornece informações úteis para a análise de investimento, pois o valor contábil é um grau relativamente constante e pode ser comparado com o valor de mercado. O autor salienta que o índice PBV é usado para comparar empresas similares, indicando uma sub ou supervalorização das organizações. Além disso, empresas com resultados negativos não podem ser avaliadas pelo PER, mas podem ser avaliadas pelo PBV. O índice PBV é determinado da seguinte maneira:

$$
\text { Price Book Value }(\mathrm{PBV})=\frac{\text { Valor de Mercado }}{\text { Valor Contábil por ação }}
$$

Para que uma empresa tenha um crescimento no mercado de capitais, primeiramente necessita de um forte e consistente crescimento das vendas. Assim surje o Price Sales Ratio (PSR), que indica a relação entre o valor de mercado e a receita líquida (PINHEIRO, 2012). Conforme Damodaran (1997), este índice é calculado como o valor total de mercado de uma empresa (valor da ação vezes quantidade de ações), dividido por suas vendas liquidas por ação. Deste modo, o PSR indica quanto que o mercado está disposto a pagar pelas receitas da empresa (DAMODARAN, 1997). A relação do valor de mercado e a receita líquida é determinado da seguinte forma:

$$
\text { Price Sales Ratio }(\mathrm{PSR})=\frac{\text { Valor de Mercado }}{\text { Receita Líquida por ação }}
$$

O índice que relaciona diretamente os dividendos distribuídos com o valor da ação é chamado de Price cash dividends (PCD) ou Dividend Yield, este indicador representa a proporção dos lucros que são entregues aos acionistas (ASSAF NETO, 2010; PINHEIRO, 2012). Conforme Pinheiro (2012, p. 492), o PCD “[...] é um dos dois 
componentes da rentabilidade global para o acionista, sendo o outro componente a maisvalia ou menos-valia gerada no momento do desinvestimento." A relação entre os dividendos pagos aos acionistas e o valor de mercado é determinado da seguinte maneira:

$$
\text { Price Cash Dividends }(\mathrm{PCD})=\frac{\text { Dividendo por ação }}{\text { Valor de Mercado }}
$$

Conforme descritos nesta seção, cada indicador possui uma visão diferenciada para analisar o valor da empresa, especificamente a partir dos valores de mercado.

\subsection{Métodos Multicritério para Tomada de Decisão}

Os métodos multicritério para tomada de decisão, conforme Gomes e Gomes (2012, p. 21), são técnicas que "servem para selecionar, ordenar, classificar ou descrever detalhadamente as alternativas mediante as quais se tomará a decisão." A escolha de qual método a ser empregado nas pesquisas depende do tipo de problema de pesquisa, dos pesquisadores envolvidos, da estrutura de pesquisa e do tipo de resposta que se deseja alcançar (GOMES; GOMES, 2012). Segundo Roy (1996), os métodos multicritério são escolhidos dependendo do problema, da classificação e da ordenação das alternativas existentes no problema.

Roy (1996) apresentou o seguinte padrão de problemas nos métodos multicritério: 1) $\alpha$ escolha - escolher a melhor alternativa de um conjunto de alternativas disponíveis; 2) $\beta$ classificação - classificar as alternativas de um conjunto de alternativas disponíveis em grupos relativamente homogêneos; 3) $\gamma$ ranking - classificação das alternativas de um conjunto de alternativas disponíveis, do melhor ao pior; e 4) $\delta$ descrição - descrever as alternativas de um conjunto de alternativas disponíveis em termos de suas peculiaridades e características.

O campo de estudo dos métodos multicritério para tomada de decisão foi robustamente desenvolvido a partir da década de 1960. Um dos primeiros métodos que descrevem a avaliação multicritério foi criado por MacCrimmon (1968), denominado de Simple Additive Weighing (SAW). Posteriormente, Keeney e Raiffa (1976) avançaram no campo dos estudos multicritério, o qual atribuiu uma função de utilidade múltipla na análise.

Os métodos de correlação de ranking foram os primeiros a serem aplicados na análise multicritério. A correlação foi introduzida pela primeira vez pelo psicólogo Spearman (1904) e posteriormente pelo estatístico Kendall (1970).

Dentre os métodos multicritério para tomada de decisão, há aqueles que pertencem à família dos métodos de subordinação (outranking) desenvolvidos com a finalidade de auxiliar no processo de tomada de decisão, como o ELECTRE (ROY, 1968) e NAIADE (MUNDA, 1995).

Outra linha existente nos métodos multicritério são as técnicas utilizadas para a definição dos pesos dos critérios. A mais conhecidas e mais utilizadas pelo meio acadêmico são a Entropia, elaborada por Shannon (1948), o Método Analítico Hierárquico (AHP), proposto e desenvolvido por Saaty (1980) e a Teoria dos Conjuntos Fuzzy, com o AHP de Buckley (1987). Por fim, há as técnicas de rankings, denominadas de métodos de agregação com função valor aditiva, como o VIKOR (DUCKSTEIN; OPRICOVIC, 1980), TOPSIS (HWANG; YOON, 1981), PROMETHEE (BRANS; VINCKE; MARESCHAL, 1986), COPRAS (ZAVADSKAS et al. 1994) e o MOORA (BRAUERS; ZAVADSKAS, 2006).

Neste estudo, foi utilizada a técnica de Entropia para a formação dos pesos das 
variáveis, o algoritmo de VIKOR para a determinação do ranking dos indicadores e a correlação de Kendall, com o objetivo de comparação dos rankings. Na próxima seção, é descrito o método VIKOR.

\subsection{Método de VIKOR}

O método ViseKriterijumska Optimizacija i Kompromisno Resenje (VIKOR) ou "Otimização Multicritério e Solução de Compromisso" é uma técnica estatística introduzida dentro das abordagens da Teoria Multiple Criteria Decision Making (MCDM). A técnica foi desenvolvida por Serafim Opricovic em 1979, publicado em 1980 pela revista Water Resources Research (DUCKSTEIN; OPRICOVIC, 1980). O $V I K O R$ foi desenvolvido a partir da métrica utilizada no método de programação compromisso introduzido em MCDM por Yu (1973).

O algoritmo de VIKOR possui como objetivos a determinação de um ranking de compromisso, a solução de compromisso e os intervalos de estabilidade de peso para a estabilidade preferencial da solução de compromisso obtido com os pesos iniciais (DUCKSTEIN; OPRICOVIC, 1980). O VIKOR se concentra em elaborar um ranking a partir de um conjunto de alternativas de critérios contraditórios presentes, o qual apresenta uma classificação multicritério com base na medida especial de proximidade com a solução ideal (DUCKSTEIN; OPRICOVIC, 1980).

$\mathrm{O}$ ranking de compromisso formado pelo algoritmo de VIKOR possui quatro etapas, como segue:

Passo 1: Determinar os maiores valores $f_{i}^{*}$ e os menores valores $f_{i}^{-}$de toda a função, $i=1,2, \ldots, \mathrm{n}$.

$$
f_{i}^{*}=\max _{j} f_{i j} \quad f_{i}^{-}=\min _{j} f_{i j}
$$

Onde:

$f_{i}^{*}$ : maior valor apresentado pelo indicador i pelo conjunto de empresa;

$f_{i}^{-}$: menor valor apresentado pelo indicador i pelo conjunto de empresa; e

$f_{i j}$ : o valor do indicador i atribuído a empresa $\mathrm{j}$.

Passo 2: Calcular os valores $S_{j}$ (é o grupo de utilidade máxima) e $R_{j}$ (é o peso individual mínimo), $j=1,2, \ldots, J$, nas relações, em que $w_{i}$ são os pesos dos critérios, neste estudo os pesos foram obtidos a partir do cálculo da entropia.

$$
\begin{aligned}
S_{j} & =\frac{\sum_{i=1}^{n} w_{i}\left(f_{i}^{*}-f_{i j}\right)}{\left(f_{i}^{*}-f_{i}^{-}\right)} \\
R_{j} & =\max _{j}\left[\frac{w_{i}\left(f_{i}^{*}-f_{i j}\right)}{\left(f_{i}^{*}-f_{i}^{-}\right)}\right]
\end{aligned}
$$

Onde:

$S_{j}$ : grupo de utilidade máxima da empresa j;

$w_{i}$ : pesos dos critérios obtidos por meio do cálculo da entropia;

$f_{i}^{*}$ : maior valor apresentado pelo indicador i atribuído pelo conjunto de empresa; 
$f_{i j}$ : o valor do indicador i atribuído a empresa $\mathrm{j}$;

$f_{i}^{-}$: menor valor apresentado pelo indicador i pelo conjunto de empresa; e

$R_{j}$ : peso individual mínimo da empresa $\mathrm{j}$.

Passo 3: Calcular os valores $Q_{j}, j=1,2, \ldots, J$, pela relação, em que $S^{*}=\min _{j} S_{j}$, $S^{-}=\max _{j} S_{j}$ e $R^{*}=\min _{j} R_{j}, R^{-}=\max _{j} R_{j}$, o $v$ é introduzido como peso de estratégia geralmente utilizado como $v=0,5$.

$$
Q_{j}=\frac{v\left(S_{j}-S^{*}\right)}{\left(S^{-}-S^{*}\right)}+\frac{(1-v)\left(R_{J}-R^{*}\right)}{\left(R^{-}-R^{*}\right)}
$$

Onde:

$\mathrm{v}=0,5$;

$Q_{j}:$ score final da empresa $\mathrm{j}$;

$S_{j}$ : grupo de utilidade máxima da empresa j;

$S^{*}$ : menor grupo de utilidade máxima do conjunto de empresa;

$S^{-}$: maior grupo de utilidade máxima do conjunto de empresa;

$R_{j}$ : peso individual mínimo;

$R^{*}$ : menor peso individual mínimo; e

$R^{-}$: maior peso individual mínimo.

Passo 4: Classificar as alternativas de forma decrescente, pelos valores obtidos por S, R e Q. Os resultados são três listas de classificação. Contudo, pode-se considerar apenas os valores obtidos por $\mathrm{Q}$.

$\mathrm{O}$ algoritmo de VIKOR foi aplicado em diversos campos das ciências, tais como transporte público (TZENG et al., 2005), formulação de políticas (YANG; WANG, 2006) e planejamento de recursos hídricos (OPRICOVIC, 2011).

\section{MÉTODO E PROCEDIMENTOS DA PESQUISA}

Este estudo caracteriza-se inicialmente quanto ao objetivo da pesquisa, como uma pesquisa descritiva, pois busca estabelecer o grau de relação entre a eficiência de mercado de capitais e a eficiência econômico-financeira, nas empresas brasileiras pertencentes ao índice IBrX-50 da BM\&FBovespa. Em relação aos procedimentos adotados neste estudo, tem-se uma pesquisa documental. Assim, os indicadores econômico-financeiros e de mercado de capitais, foram coletados das demonstrações financeiras das empresas, por meio do sítio da Thomson One Banker. No que tange à abordagem dada ao problema de pesquisa, classifica-se o presente estudo em quantitativa, devido ao uso de instrumentos estatísticos nas fases de coleta, tratamento e análise dos dados.

A população de pesquisa compreende empresas pertencentes ao Índice Brasil 50 (IBrX-50) listadas na BM\&FBovespa, perfazendo um total de 50 companhias. Entretanto, dentre essas 50 a Petrobras e a Vale estão listadas duas vezes, pois possuem tanto ações ordinária nominativa como preferencial nominativa. Assim, apenas 48 empresas compõem a população. As empresas do índice IBrX-50 foram escolhidas para compor a pesquisa, pois este índice mede o retorno de uma carteira de ações composta por 50 ações mais negociadas na BM\&FBovespa em termos de liquidez, ponderadas na carteira pelo valor de mercado das ações disponíveis para negociação.

Já a amostra, em decorrência dos períodos analisados, a amostra da pesquisa 
compreendeu as 27 empresas listadas na BM\&FBovespa, pertencentes ao índice IBrX50, que apresentavam todos os indicadores de mercado de capitais e econômicofinanceiros, no período de 2008 a 2012. Quanto a análise da pesquisa, utilizou-se a entropia para a definição dos pesos dos critérios, o VIKOR para formação dos rankings (mercado de capitais e econômico-financeiros) e a correlação de Kendall para efetuar a comparação entre os rankings.

\section{APRESENTAÇÃO ANÁLISE DOS RESULTADOS}

Este tópico é responsável por apresentar os rankings formados pelos indicadores de mercado de capitais e pelos indicadores econômico-financeiros. Observa-se que foram analisadas 27 empresas em cinco anos e para uma análise mais objetiva, foram analisadas apenas as empresas que ocuparam as primeiras posições no ranking dos indicadores de mercado de capitais e econômico-financeiros. A Tabela 1 apresenta o ranking dos indicadores econômico-financeiros e dos indicadores de mercado de capitais

Tabela 1 - Ranking dos indicadores econômico-financeiros e dos indicadores de mercado de capitais

\begin{tabular}{|c|c|c|c|c|c|c|c|c|c|c|}
\hline \multirow{2}{*}{ Empresas } & \multicolumn{5}{|c|}{ Posição - Econômico-financeiros } & \multicolumn{5}{|c|}{ Posição - Mercado de Capitais } \\
\hline & 2008 & 2009 & 2010 & 2011 & 2012 & 2008 & 2009 & 2010 & 2011 & 2012 \\
\hline All América Latina Logística S.A. & 20 & 24 & 25 & 21 & 17 & 26 & 1 & 6 & 23 & 13 \\
\hline BRF-Brasil Foods S.A. & 24 & 25 & 26 & 17 & 18 & 2 & 2 & 11 & 16 & 2 \\
\hline CCR S.A. & 4 & $\mathbf{8}$ & 11 & 9 & 6 & 11 & 7 & 4 & 10 & 5 \\
\hline CIA Hering & 15 & 5 & 4 & 5 & 4 & 21 & 17 & 8 & 6 & 10 \\
\hline Companhia Brasileira Distribuição S.A. & 22 & 21 & 22 & 19 & 11 & 12 & 22 & 12 & 24 & 14 \\
\hline Companhia de Bebidas das Américas & 13 & 6 & 6 & 6 & 5 & 9 & 13 & 5 & 3 & 8 \\
\hline Companhia Siderúrgica Nacional & 1 & 3 & 5 & 4 & 24 & 7 & 8 & 9 & 11 & 27 \\
\hline Embraer S.A. & 21 & 12 & 18 & 23 & 13 & 15 & 27 & 14 & 13 & 20 \\
\hline Gafisa S.A. & 19 & 20 & 19 & 27 & 25 & 23 & 26 & 19 & 26 & 24 \\
\hline Gerdau S.A. & 12 & 22 & 21 & 20 & 19 & 20 & 14 & 15 & 21 & 16 \\
\hline JBS S.A. & 25 & 26 & 27 & 26 & 21 & 1 & 3 & 27 & 27 & 12 \\
\hline Klabin S.A. & 27 & 14 & 20 & 22 & 10 & 27 & 19 & 21 & 15 & 18 \\
\hline Localiza Rent A Car S.A. & 6 & 13 & 8 & 10 & 8 & 16 & 12 & 10 & 18 & 6 \\
\hline Lojas Americanas S.A. & 5 & 4 & 1 & 3 & 3 & 4 & 4 & 1 & 9 & 1 \\
\hline Lojas Renner S.A. & 10 & 7 & 7 & 7 & 7 & 17 & 11 & 7 & 4 & 7 \\
\hline Natura Cosméticos S.A. & 2 & 2 & 2 & 2 & 2 & 6 & 6 & 2 & 2 & 3 \\
\hline OI S.A. & 14 & 27 & 13 & 18 & 20 & 10 & 18 & 17 & 8 & 15 \\
\hline PDG Realty S.A. & 16 & 15 & 16 & 13 & 27 & 24 & 21 & 22 & 22 & 22 \\
\hline Petróleo Brasileiro S.A. - Petrobras & 9 & 11 & 17 & 15 & 16 & 18 & 24 & 24 & 20 & 21 \\
\hline Rossi Residencial S.A. & 17 & 18 & 15 & 12 & 26 & 25 & 25 & 20 & 19 & 23 \\
\hline Souza Cruz S.A. & 3 & 1 & 3 & 1 & 1 & 5 & 10 & 3 & 1 & 4 \\
\hline Suzano Papel E Celulose S.A. & 26 & 10 & 24 & 25 & 22 & 22 & 20 & 26 & 7 & 26 \\
\hline Telefônica Brasil S.A. & 7 & 9 & 12 & 14 & 14 & 8 & 9 & 13 & 5 & 17 \\
\hline TIM Participações S.A. & 23 & 23 & 10 & 16 & 12 & 3 & 5 & 25 & 17 & 19 \\
\hline Ultrapar Participações S.A. & 18 & 17 & 14 & 11 & 9 & 13 & 15 & 18 & 14 & 9 \\
\hline Usinas Sider. Minas Gerais S.A. - Usiminas & 11 & 19 & 23 & 24 & 23 & 14 & 23 & 16 & 25 & 25 \\
\hline Vale S.A. & 8 & 16 & 9 & 8 & 15 & 19 & 16 & 23 & 12 & 11 \\
\hline $\begin{array}{l}\text { Indicador com maior poder de explicação } \\
\text { (entropia) }\end{array}$ & ROE & ROE & ROE & ROE & ROE & PER & PER & PER & PER & PER \\
\hline $\begin{array}{l}\text { Indicador com menor poder de explicação } \\
\text { (entropia) }\end{array}$ & GAT & LS & GAT & GAT & GAT & PSR & PSR & PSR & PSR & PSR \\
\hline
\end{tabular}

PER: Price Earning Ratio; PSR: Price Sales Ratio; LS: Liquidez Seca; GAT: Giro do Ativo Total; e ROE: Rentabilidade do Patrimônio Líquido.

Fonte: Dados da pesquisa.

Segundo o exposto na Tabela 1, no ano de 2008 a empresa JBS S.A. foi a que apresentou um melhor desempenho de mercado dentre as empresas pesquisadas, porém no ranking econômico-financeiro passa a ser a $25^{\circ}$ colocada. Conforme os cálculos das entropia, os indicadores com maior poder de explicação nos de mercado de capitais 
foram o PER, visto que a empresa JBS S.A. obteve altos valores nestes indicador, ficou como primeira colocada no ranking.

Entre os indicadores econômico-financeiros, aquele que possui o maior poder de entropia foi o ROE, a JBS S.A. obteve um ótimo desempenho de PER, ou seja, seu preço em relação ao lucro era muito alto. Assim era de se esperar que a empresa apresentasse um baixo ROE, pois representa a relação do lucro com patrimônio líquido, o que afetou sua posição no ranking econômico-financeiro. Nos outros anos em análise, a empresa passa a alternar de posição, ocorrendo até de ocupar as piores posições no ranking de mercado de capitais.

A empresa Companhia Siderúrgica Nacional foi a melhor colocada no desempenho econômico-financeiro no ano de 2008, nos outros anos analisados passa a ser a $3^{\circ}, 5^{\circ}, 4^{\circ}, 24^{\circ}$ colocada, ou seja, a sua rentabilidade do patrimônio líquido em 2009 a 2012 foi menor que das organizações pertencentes a amostra. Quanto a sua posição no ranking de mercado de capitais, sua pior colocação quando comparado ao econômicofinanceiro, foi em 2012, visto que ficou em $27^{\circ}$ colocada. A empresa obteve posições próximas nos dois rankings em 2012 e conforme os resultados financeiros da empresa, tem-se as seguintes conclusões: a empresa obteve um prejuízo no ano de 2012, o que ocasionou um PER negativo, visto que é o indicador com o maior poder de explicação, sua posição no ranking foi prejudicada, e por ter tido prejuízo, seu ROE também foi negativo, o que afetou sua posição no ranking.

Em 2009 a melhor colocada no ranking de mercado de capitais foi a All América Latina Logística S.A., passando para sexta colocada em $2010,23^{\circ}$ e para $13^{\circ}$ colocada em 2011 e 2012, ou seja, os valores dos indicadores com maior poder explicativo, com o passar dos anos foi menor que das outras empresas. Já no ranking econômico-financeiro suas posições foram contraditórias, nos anos de 2009 e 2010, ou seja, teve baixa colocação nono ranking de econômico-financeiro, porém nos anos de 2008, 2011 e 2012 as posições entre os rankings foram próximas. No ano de 2009 a All América Latina Logística S.A. obteve um baixo resultado líquido comparado aos outros anos e apresentou o melhor PER que as outras empresas composta na amostra. Entretanto, em 2010 seu lucro líquido foi razoavelmente parecido com os anos de 2008, 2011 e 2012, mas dentre as empresas a All América Latina Logística S.A em 2010 foi novamente a que apresentou o melhor PER. Visto que o PBV foi a segunda variável com o maior poder explicativo entre os indicadores de mercado de capitais, afetou a posição da empresa, pois apresentou um PBV mediano no ano de 2010, ocupando dessa forma a $6^{\circ}$ colocação.

Destaca-se também a Souza Cruz S.A. que foi primeira colocada no ranking econômico-financeiro nos anos de 2009, 2011 e 2012, ou seja, foi a empresa que apresentou melhor retorno sobre o patrimônio líquido. Já sua colocação no ranking formado pelos indicadores de mercado de capitais, foram similares, apenas em 2010 que ocorreu um distanciamento de posições. A Souza Cruz S.A. não apresentou um dos melhores PER nos períodos analisados, contudo quanto aos outros indicadores, a empresa demonstrou um dos melhores PCD (2008, 2009 e 2011) e PBV (2008, 2009, 2010, 2011 e 2012). Observa-se que mesmo ocorrendo de 2009 a empresa ter obtido ótimos valores quanto ao PCD e PBV, seu PER foi muito baixo comparado as outras empresas, afetando dessa forma seu posicionamento no ranking de mercado de capitais.

Ainda de acordo com a Tabela 1, destaca-se a empresa Lojas Americanas S.A. como a melhor colocada no ranking de mercado de capitais e dos indicadores econômico-financeiros em 2010, apresentando uma posição considerada mediana no ranking de mercado de capitais apenas em 2011. As Lojas Americanas S.A. foi uma das 
cinco empresas com melhores valores de PER e PBV e o ROE. O único ano que ocorreu uma dessemelhança de posições, foi em 2011 , em que a empresa ocupou a $9^{\circ}$ posição no ranking de mercado de capitais e a $3^{\circ}$ nos indicadores econômico-financeiros. Isso ocorreu, pois os escores obtidos pelas variáveis PER e PBV não conseguiram compensar seu baixo PCD. Dessa forma, as Lojas Americanas S.A. é uma empresa preocupada com o seu desempenho futuro e sua valorização, por outro lado, não se preocupa com a proporção dos lucros que são entregues aos acionistas.

De forma geral, observou-se dois resultados: primeiro que existem empresas com posicionamentos similares nos dois rankings, ou seja, quanto melhor for a colocação em um ranking melhor será na outra e vice e versa; segundo, que nos mesmos anos em que ocorreu a primeira situação, existem empresas que tiveram colocações distintas. Para uma melhor análise destes achados, foi calculada a correlação de Kendall, cujos resultados estão expostos na Tabela 2.

Tabela 2 - Correlação entre os rankings de mercado de capitais e econômico-financeiros

\begin{tabular}{c|c|c}
\hline Mercado de Capitais & & Econômico-financeiros \\
\hline \multirow{2}{*}{2008} & Correlação de Kendall & $\mathbf{0 , 2 1 9 4}$ \\
\cline { 2 - 3 } & Sig. & $\mathbf{0 , 1 0 8 4}$ \\
\hline \multirow{2}{*}{2009} & Correlação de Kendall & $\mathbf{0 , 0 8 2 6}$ \\
\cline { 2 - 3 } & Sig. & $\mathbf{0 , 5 4 5 5}$ \\
\hline \multirow{2}{*}{2010} & Correlação de Kendall & $\mathbf{0 , 4 1 8 8}$ \\
\cline { 2 - 3 } & Sig. & $\mathbf{0 , 0 0 2 2}$ \\
\hline \multirow{2}{*}{2011} & Correlação de Kendall & $\mathbf{0 , 5 2 7 1}$ \\
\cline { 2 - 3 } & Sig. & $\mathbf{0 , 0 0 0 1}$ \\
\hline \multirow{2}{*}{2012} & Correlação de Kendall & $\mathbf{0 , 5 6 7 0}$ \\
\cline { 2 - 3 } & Sig. & $\mathbf{0 , 0 0 0 0}$ \\
\hline
\end{tabular}

Fonte: Dados da pesquisa.

Conforme evidenciado na Tabela 2, não se constatou correlação significante entre os rankings de mercado de capitais e econômico-financeiros calculados pelo método multicritério para tomada de decisão VIKOR, nos anos de 2008 e 2009. Dessa forma, para estes dois anos não há correlação ordinal entre os rankings formado pelos indicadores de mercado de capitais e pelos indicadores econômico-financeiros das empresas pertencentes ao índice IBrX-50.

Um dos motivos da não ocorrência de relação entre os rankings no ano de 2008, são as posições das empresas nos rankings, visto que algumas organizações ficaram em posições distintas nos rankings e outras em posições próximas. Observa-se que a três primeiras colocadas no ranking de mercado de capitais, JBS S.A., BRF-Brasil Foods S.A. e CCR S.A. ficaram com uma das últimas posições no ranking de indicadores econômico-financeiros. Já a Klabin S.A. que ficou em $27^{\circ}$ posição no ranking de mercado de capitais e no econômico-financeiro, e as empresas Lojas Americanas S.A. e Telefônica Brasil S.A. que tiveram uma diferença de apenas duas posições nos rankings. Verifica-se que estes resultados podem ter influenciado na não significância na correlação. O mesmo ocorreu no ano de 2009, as empresas All América Latina Logística S.A., BRF-Brasil Foods S.A. e JBS S.A. com as posições $1^{\circ}, 2^{\circ}$ e $3^{\circ}$ respectivamente no ranking de mercado de capitais e $24^{\circ}, 25^{\circ}$ e $26^{\circ}$ posição no ranking de indicadores econômico-financeiros, uma distância bastante representativa. Logo, Lojas Americanas S.A., Telefônica Brasil S.A. e Vale S.A. que ficaram com as mesmas posições nos rankings de indicadores de mercado de capitais e econômico-financeiros. Igualmente com o ano de 2008, essa variabilidade de posições e de proximidade, influenciou na 
correlação.

Ainda segundo a Tabela 2, os rankings de mercado de capitais e econômicofinanceiro determinados pelo método VIKOR, nos anos de 2010, 2011 e 2012 apresentaram uma correlação positivamente significativa. Assim, nestes três anos em análise é possível aceitar de que há correlação ordinal entre os rankings formado pelos indicadores de mercado de capitais e pelos indicadores econômico-financeiros das empresas pertencentes ao índice $\mathrm{IBrX}-50$. Estes achados demonstram que as empresas pertencentes do índice IBrX-50 que possuem um bom desempenho nos indicadores econômico-financeiro, também apresentam um bom desempenho nos indicadores de mercado de capitais.

\section{CONSIDERAÇÕES FINAIS}

Esta pesquisa teve como objetivo estabelecer o grau de relação entre a eficiência de mercado de capitais, a eficiência econômico-financeiro e o valor correspondente da ação, nas empresas brasileiras pertencentes ao índice IBrX-50. Para responder aos objetivos da pesquisa, realizou-se uma pesquisa descritiva, com procedimento de pesquisa documental e com uma abordagem quantitativa.

Para realizar a análise, foram definidos os pesos dos indicadores de mercado de capitais e econômico-financeiros por meio da entropia. Em seguida, elaboraram-se dois rankings, um formado pelos indicadores de mercado de capitais e o outro pelos indicadores econômico-financeiros, por meio do método VIKOR. Ao final, utilizou-se o coeficiente de correlação de Kendall para determinar o grau de relacionamento entre os rankings.

Quanto ao ranking de eficiência econômico-financeira, destacam-se o posicionamento de algumas empresas como a Companhia Siderúrgica Nacional, Souza Cruz S.A. e Lojas Americanas S.A. A Souza Cruz S.A. se destaca ainda mais por ter tido a melhor classificação em três anos analisados $(2009,2011$ e 2012) e terceira classificada em dois anos (2008 e 2010). Ressalta-se também, de forma negativa, empresas como a Klabin S.A., OI S.A., JBS S.A., Gafisa S.A. e PDG Realty S.A. De forma geral, é possível verificar que ocorreu apenas em dois anos de empresas que assumiram a primeira colocação no ranking de mercado de capitais, assumirem a primeira colocação quanto ao ranking econômico-financeiro, o mesmo ocorreu para aquelas que ficaram em última colocação.

Para o ranking de mercado de capitais criado pelo método VIKOR, destacam-se as empresas JBS S.A. (2008), All America Latina Logística S.A. (2009), Lojas Americanas S.A. (2010 e 2012) e Souza Cruz S.A. (2011), por se apresentarem como as melhores no aspecto de mercado de capitais. A Klabin S.A. (2008), Embraer S.A. (2009), JBS S.A. (2010 e 2011) e Companhia Siderúrgica Nacional (2012), emergem como as piores empresas na classificação feita pelos indicadores de mercado de capitais. Observa-se que a empresa JBS S.A., mudou de primeira colocada (2008) para última colocada em 2010 e 2011, ou seja, seus indicadores de mercado de capitais diminuíram drasticamente entre os anos.

O objetivo da pesquisa consistiu em estabelecer o grau de relacionamento entre o ranking de indicadores de mercado de capitais e o ranking de indicadores econômicofinanceiros, de empresas brasileiras, por meio do coeficiente de correlação de Kendall. Nesse sentido, para ambos os rankings elaborados pelo método VIKOR foram constatadas correlações positivamente significativas no anos de 2010, 2011 e 2012, não apresentando correlação significativa em 2008 e 2009. Sendo assim, há correlação 
ordinal positiva e significativa entre os rankings formado pelos indicadores de mercado de capitais e pelos indicadores econômico-financeiros das empresas brasileiras, foi aceita apenas para os três últimos anos. Portanto, conclui-se que as empresas para alguns anos em análise, tendem a possuírem similaridades nas posições dos indicadores de mercado de capitais e nos indicadores econômico-financeiros tradicionais, mas em outros apresentaram tanto posições similares como distintas.

Considerando-se o que foi exposto nas limitações do estudo, apresentam-se as recomendações para futuras pesquisas: reaplicar o estudo em outros grupo de empresas da BM\&FBovespa, de modo a identificar as particularidades destes grupos frente a eficiência do mercado de capitais e do desempenho econômico-financeiro das empresas; ampliar o período de análise, a fim de averiguar com uma maior profundidade o desempenho das empresas pertencentes ao índice IBrX-50; alterar o conjunto de indicadores econômico-financeiros e de mercado de capitais utilizados, visto que o uso de outros indicadores pode influenciar nos resultados; e aplicar outros instrumentos estatísticos para averiguar a relação entre a eficiência do mercado de capitais e do desempenho econômico-financeiro das empresas.

\section{REFERÊNCIAS}

ASSAF NETO, Alexandre. Finanças corporativas e valor. 5. ed. São Paulo: Atlas, 2010.

BRANS, Jean-Pierre; VINCKE, Ph.; MARESCHAL, Bertrand. How to select and how to rank projects: The PROMETHEE method. European Journal of Operational Research, v. 24, p. 228-238, 1986.

BREALEY, Richard A.; MYERS, Stewart C. Finanças corporativas: investimento de capital e avaliação. Porto Alegre: Bookman, 2006.

BRIGHAM, Eugene F.; EHRHARDT, Michael C. Administração financeira: teoria e prática. São Paulo: Thomson, 2006.

DAMODARAN, Aswath. Avaliação de investimentos: ferramentas e técnicas para a determinação do valor de qualquer ativo. Rio de Janeiro: Qualitymark, 1997.

DUCKSTEIN, Lucien; OPRICOVIC, Serafim. Multiobjective optimization in river basin development. Water Resources Research, v. 16, n. 1, p. 14-20, feb. 1980.

FAMA, Eugene F. Efficient capital markets: a review of theory and empirical work. The Journal of Finance, v. 25, n. 2, p. 383-417, may 1970.

GOMES, Luiz Flavio Autran Monteiro; GOMES, Carlos Francisco Simões. Tomada de decisão gerencial: enfoque multicritério.4. ed. São Paulo: Atlas, 2012.

GONTIJO, Arimar Colen; MAIA, Claudia Santos Castro. Tomada de decisão, do modelo racional ao comportamental: uma síntese teórica. Revista Caderno de Pesquisas em Administração, v. 11, n. 4, p. 13-30, out./dez. 2004.

GORDON, Myron J.; SHAPIRO, Eli. Capital equipment analysis: the required rate of profit. Management Science, v. 3, n. 1, p. 102-110, oct. 1956. 
HWANG, Ching-Lai; YOON, Kwangsun. Multiple attribute decision making: methods and applications. Berlin: Springer, 1981.

IUDÍCIBUS, Sérgio de. Análise de balanços. 10. ed. São Paulo: Atlas, 2009.

KEENEY, Ralph L.; RAIFFA, Howard. Decisions with multiple objectives: preferences and value trad-offs. New York: Wiley, 1976.

KENDALL, Maurice G. Rank correlation methods. London: Charles Griffin \& Co, 1970.

MACCRIMMON, K. R. Decisionmaking among multiple-attribute alternatives: a survey and consolidated approach. CA: RAND Corporation, 1968.

MARKOWITZ, Harry. Portfolio selection. The Journal of Finance, v. 7, n. 1, p. 77-91, mar. 1952.

MATARAZZO, Dante Carmine. Análise financeira de balanços: abordagem gerencial. 7. ed. São Paulo: Atlas, 2010.

MUNDA, Giuseppe. Multicriteria evaluation in a fuzzy environment: theory and applications in ecological. Heidelberg: Physica-Verlag, 1995.

OHLSON, James A. Earning, book value, and dividends in equity valuation.

Contemporany Accounting Research, v. 11, n. 2, p. 661-687, 1995.

OPRICOVIC, Serafim. Fuzzy VIKOR with an application to water resources planning. Expert Systems with Apliccations, v. 38, n. 10, p. 12983-12990, sep. 2011.

PINHEIRO, Juliano Lima. Mercado de capitais: fundamentos e técnicas. 6. ed. São Paulo: Atlas, 2012.

ROY, Bernard. Classement et choix en présence de points de vue multiples (la méthode ELECTRE). La Revue d'Informatique et de Recherche Opérationelle, v. 2, n. 8, p. 57-75, 1968.

ROY, Bernard. Multicriteria methodology goes decision aiding. Netherlands: Kluwer Academic Plublishers, 1996.

SAATY, Thomas L. The Analytic Hierarchy Process. New York: McGraw-Hill, 1980.

SHANNON, Claude E. A mathematical theory of communication. The Bell System Technical Journal, v. 27, jul./oct. 1948.

SHARPE, William F. A theory of market equilibrium under conditions of risk. The Journal of Finance, v. 19, n. 3, p. 425-442, sep. 1964.

SPEARMAN, Charles. The proof and measurement of association between two things. The American Journal of Psychology, v. 15, n. 1, p. 72-101, jan. 1904.

TZENG, Gwo-Hshiung; LIN, Cheng-Wei; OPRICOVIC, Serafim. Multi-criteria analysis 
of alternative-fuel buses for public transportation. Energy Policy, v. 33, p. 1373-1383, 2005 .

YANG, Chyan; WANG, Tsung-Cheng. VIKOR method analysis of interactive trade in policy-making. The Business Review, v. 6, n. 2, p. 77-85, 2006.

YU, Po Lung. A class of solutions for group decision problems. Management Science, v. 19, n. 8, p. 936-946, 1973.

ZAVADSKAS, Edmundas Kazimieras; KAKLAUSKAS, Arturas; Sarka, V. The new method of multicriteria complex proportional assessment of projects. Technological and Economic Development of Economy, v. 1, n. 3, p. 131-139, 1994. 